\title{
Dose-response patterns for vibration-induced white finger
}

\author{
M J Griffin, M Bovenzi, C M Nelson
}

Occup Environ Med 2003;60: 16-26

See end of article for authors' affiliations

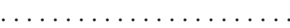

Correspondence to: Professor M J Griffin, Human Factors Research

Unit, Institute of Sound and Vibration Research, University of Southampton, Southampton SO 17 1BJ, UK:

M.J.Griffin@soton.ac.uk

Accepted 5 June 2002

\begin{abstract}
Aims: To investigate alternative relations between cumulative exposures to hand-transmitted vibration (taking account of vibration magnitude, lifetime exposure duration, and frequency of vibration) and the development of white finger (Raynaud's phenomenon).

Methods: Three previous studies have been combined to provide a group of 1557 users of powered vibratory tools in seven occupational subgroups: stone grinders, stone carvers, quarry drillers, dockyard caulkers, dockyard boilermakers, dockyard painters, and forest workers. The estimated total operating duration in hours was thus obtained for each subject, for each tool, and for all tools combined. From the vibration magnitudes and exposure durations, seven alternative measurements of cumulative exposure were calculated for each subject, using expressions of the form: dose $=\sum a_{i}^{m} t_{i \prime}$ where $a_{i}$ is the acceleration magnitude on tool $i, t_{i}$ is the lifetime exposure duration for tool $i$, and $m=$ $0,1,2$, or 4 .

Results: For all seven alternative dose measures, an increase in dose was associated with a significant increase in the occurrence of vibration-induced white finger, after adjustment for age and smoking. However, dose measures with high powers of acceleration $(m>1)$ faired less well than measures in which the weighted or unweighted acceleration, and lifetime exposure duration, were given equal weight $(m=1)$. Dose determined solely by the lifetime exposure duration (without consideration of the vibration magnitude) gave better predictions than measures with $m$ greater than unity. All measures of dose calculated from the unweighted acceleration gave better predictions than the equivalent dose measures using acceleration frequency-weighted according to current standards.

Conclusions: Since the total duration of exposure does not discriminate between exposures accumulated over the day and those accumulated over years, a linear relation between vibration magnitude and exposure duration seems appropriate for predicting the occurrence of vibration-induced white finger. Poorer predictions were obtained when the currently recommended frequency weighting was employed than when accelerations at all frequencies were given equal weight. Findings suggest that improvements are possible to both the frequency weighting and the time dependency used to predict the development of vibration-induced white finger in current standards.
\end{abstract}

O ccupational exposures to hand-transmitted vibration result in various disorders, sometimes collectively known as the "hand-arm vibration syndrome". The syndrome includes vascular, neurological, and musculoskeletal disorders that may become manifest individually or collectively. The precise conditions causing each of these disorders are not known. However, for the best known vascular disorder, vibration-induced white finger (VWF), several studies have reported the vibration conditions associated with an observed incidence, or prevalence, of the condition.

In 1986, an annex to International Standard 5349 included a dose-response relation between the occurrence of finger blanching (that is, the onset of VWF) and three measures of exposure to hand-transmitted vibration: vibration magnitude, daily exposure duration, and years of exposure. ${ }^{1}$ The vibration acceleration was frequency-weighted, on the assumption that the effects of different vibration frequencies varied according to an experimental study of the sensations produced by handtransmitted vibration. ${ }^{2}$ The dose-response model included in the standard has allowed the severity of occupational exposures to hand-transmitted vibration to be assessed. Some subsequent epidemiological studies have reported results consistent with the predictions in the standard ${ }^{3}$; other studies have reported wide differences. ${ }^{5-8}$

With difficulties in accurately quantifying vibration exposures over many years, and some difficulty in accurately quantifying the effects of vibration exposures, a rough correspondence between the predictions of the standard and some observations may seem sufficient. However, when deciding on preventive actions, it is important to know whether changes to the vibration magnitude, or vibration frequency, or daily exposure duration, or years of exposure will change the risk of injury as predicted by the standard. At a fundamental level, there is very little information to support the form of the relations between vibration magnitude, frequency, and exposure duration as offered in the standard. ${ }^{90}$

A dose-response model for vibration-induced white finger should include the quantifiable independent variables (for example, vibration magnitude, vibration frequency, and exposure duration) known to have a large influence on the outcome (for example, the occurrence or the severity of finger blanching). Another requirement of a good quantitative model of the dose-response relation for vibration-induced white finger is that within all reasonable ranges of each model input, there must be reason to expect a positive correlation between the model predictions and the outcome found in practice. For example, an increase in vibration magnitude, or an increase in exposure duration, should result in appropriate increases in the occurrence (or severity) of finger blanching. Finally, for such a dose-response model, it would be useful to determine the accuracy of the predictions of the outcome: the accuracy will reflect the sufficiency of the model form (that is, whether all variables are appropriately included) and the effects of errors in measuring the variables. For application to reduce the injuries from hand-transmitted vibration, the model should be applicable for different tools and occupations, and not only apply approximately across a diverse range of tools and occupations. 
Table 1 Characteristics of the study populations

\begin{tabular}{|c|c|c|c|c|}
\hline Occupational group & Number & Age* & Smokers† & VWF \\
\hline Stone grinders & 188 & $39(28-48)$ & $83(44.2 \%)$ & $26(13.8 \%)$ \\
\hline Stone carvers & 237 & 41 (26-51) & $100(44.2 \%)$ & $87(36.7 \%)$ \\
\hline Quarry drillers & 145 & $43(28-51)$ & $57(39.3 \%)$ & $59(40.7 \%)$ \\
\hline Dockyard painters & 394 & $33(25-46)$ & $237(60.2 \%)$ & $65(16.5 \%)$ \\
\hline Dockyard boilermakers & 179 & $42(31-49)$ & $115(64.3 \%)$ & $37(20.7 \%)$ \\
\hline Dockyard caulkers & 94 & 31 (25-49) & 61 (64.9\%) & $51(54.3 \%)$ \\
\hline Forestry workers & 320 & $45(34-55)$ & $178(55.6 \%)$ & 107 (33.4\%) \\
\hline
\end{tabular}

This study investigated the relations between the onset of finger blanching and the characteristics of exposures to handtransmitted vibration, specifically the vibration magnitude and the daily and lifetime exposure duration. The effects of vibration frequency were investigated by comparing doseresponse models constructed with and without the current frequency weighting.

\section{METHODS OF INVESTIGATION Populations studied}

The authors have previously conducted studies of VWF with populations of dockyard workers, ${ }^{11}{ }^{12}$ forestry workers, ${ }^{13}$ and quarry/stone workers. ${ }^{14}$ In each of these studies, information on medical history, employment history, extent, severity, and development of VWF, and exposure to vibration were obtained from individual workers during interviews using a structured questionnaire. Although the questionnaires used in the three studies were not identical, there were common elements. It was possible, by combining the three sets of data, to produce a larger study group of 1557 male subjects comprising seven occupational groups: stone grinders, stone carvers, quarry drillers, dockyard caulkers, dockyard boilermakers, dockyard painters, and forestry workers.

\section{Symptoms of VWF}

Subjects were asked to state whether they had experienced finger blanching. Where the response was positive, the date at which blanching first occurred was obtained from the subject. He was also asked to describe the areas of the fingers affected in the worst attack of blanching; this enabled a numerical score of blanching severity to be established for each individual, using the system described by Griffin. ${ }^{15}$ The blanching scores correspond to areas of blanching on the digits commencing with the thumb. On the fingers a score of $\mathrm{l}$ is given for blanching on the distal phalanx, a score of 2 for blanching on the middle phalanx, and a score of 3 for blanching on the proximal phalanx. On the thumbs the scores are 4 for the distal phalanx and 5 for the proximal phalanx.

Diagnosis of VWF in individual cases is difficult because of the possibility of various other, non-occupational, causes of the symptoms and signs. Subjects were asked questions about their general medical history to identify factors likely to result in vascular or neurological symptoms or signs. Where an alternative (non-vibration) explanation was apparent for finger blanching or neurological symptoms (for example, family history of primary Raynaud's disease, injuries, medication, symptoms predating vibration exposure), the subject was excluded from the study. A total of 29 quarry and stone workers were excluded from a sample of 599; 321 dockyard workers were excluded from a sample of 1242; and 20 forestry workers were excluded from a sample of 340. Among the 1557 individuals remaining in the study population after this data cleansing procedure, any relevant symptoms and signs were assumed to be attributable to vibration exposure. The questions and the exclusions were designed so that the criteria for the diagnosis of VWF could be reasonably consistent with international recommendations at the time of the studies: (1) a positive history of cold provoked episodes of well demarcated blanching in one or more fingers after excluding primary Raynaud's disease or other secondary forms of Raynaud's phenomenon; and (2) the first appearance of finger blanching after the start of occupational exposure to hand-transmitted vibration.

The significance of the effects of smoking on the development of VWF has been studied with differing conclusions. ${ }^{9}$ In the present study, the subjects were asked about their smoking habits and categorised as either non-smokers or smokers of cigarettes, cigars, or pipes. Ex-smokers were classified as non-smokers if they had stopped smoking for more than one year.

Table 1 summarises the ages of the subjects in the seven occupational groups and the prevalence of smoking and VWF in each group.

\section{Vibration exposure}

Subjects were asked to identify (by generic type) the vibrating tools used during their working life. Tool operating durations were obtained in hours per day, days per year, and total number of years, separately for each period of use of each tool type. The estimated total (that is, lifetime) operating duration in hours was thus obtained for each subject, for each tool. The total vibration exposure duration for each subject was obtained by addition of the operating durations for the different tools. When VWF, as a binary variable (yes/no), was related to duration of vibration exposure, total operating hours and years of usage of vibratory tools were calculated as those at the time of the study (for the workers without vascular disturbances) or those at the time of the onset of symptoms (for the subjects who reported VWF). When the score of finger blanching severity, as an ordinal variable, was related to duration of vibration exposure, total operating time and years of usage of vibratory tools were calculated as those at the time of the study for both VWF and non VWF workers.

Hand-transmitted vibration was measured on representative samples of the tools used by the subjects in each of the study populations. Measurement equipment differed between the different studies; however, in all cases the measurements were made using Brüel \& Kjaer piezoelectric accelerometers, with precautions taken to prevent measurement errors from overloads, d.c. shifts, and cable movement. Vibration magnitudes were expressed as root-mean-square acceleration, frequency-weighted using frequency weighting $\mathrm{W}_{\mathrm{h}}$ in accord with ISO $5349\left(1986,{ }^{1} 200{ }^{16}\right)$. In addition, unweighted acceleration magnitudes were obtained over the same nominal frequency range $(6.3-1250 \mathrm{~Hz})$. For each tool, vibration measurements were made at each hand position in three orthogonal directions. In each case, the greatest of the three magnitudes was selected to represent the vibration magnitude of the tool. Further details are available elsewhere. ${ }^{11} 1314$ 


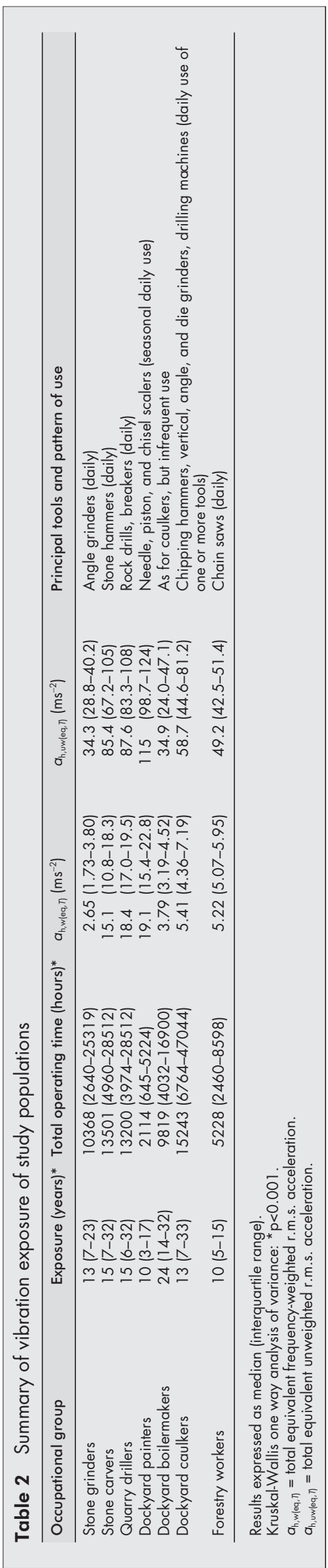

Using the vibration magnitude and exposure durations, it was possible to construct, for each subject, various alternative vibration "doses", of the general form:

dose $=\sum_{i}\left[a_{j}^{m} t_{i}\right]$

where $a_{i}$ and $t_{i}$ are the acceleration magnitude and the exposure duration respectively, for tool $i$.

In these doses, the relative importance of the acceleration, $a$, (weighted (i.e. $a_{\text {wi }}$ ) or unweighted (i.e. $a_{\text {uwi }}$ ) ) and the total exposure duration, $t$, depends on the value of $m$. If $m$ has the value 2 , the relation between $a$ and $t$ is that assumed in rootmean-square averaging (as suggested in current standards to evaluate vibration exposure over a working day, for example, ISO 5349-1, 2001 ${ }^{16}$; BS 6842, 1987 ${ }^{17}$ ). Assigning values of 1 or 4 to $m$ decreases or increases, respectively, the "importance" of the vibration magnitude, $a$, relative to that of exposure duration, $t$. With $m=0$, the dose takes no account of vibration magnitude. Doses with $m=0,1,2$, and 4 were computed for each subject, with both frequency-weighted acceleration and unweighted acceleration.

In addition to the above "doses", which all increase with increasing exposure duration, equivalent frequency-weighted acceleration r.m.s. magnitudes and unweighted r.m.s. acceleration magnitudes $\left(a_{\mathrm{h}, w(e q, T)}\right.$ and $a_{\mathrm{h}, u w(e q, T)}$ respectively) were computed for each subject:

$a_{\mathrm{h}(\mathrm{eq}, T)}=\left[\frac{\sum_{i} a_{i}^{2} t_{i}}{\sum_{i} t_{i}}\right]^{1 / 2}$

Table 2 summarises the vibration exposure patterns for the seven occupational groups.

\section{Statistical methods}

Data analysis was performed using the software Stata (version 6.0, Stata Corporation 1999). Continuous data were summarised with the median as a measure of central tendency and lower and upper quartiles as measures of dispersion. Differences between independent groups were tested by the Kruskal-Wallis one way analysis of variance. Differences between categorical data tabulated in contingency tables were tested by the $\chi^{2}$ statistic.

Unconditional logistic regression analysis was used to assess the association between VWF (binary outcome) and alternative measures of vibration dose while adjusting for potential confounding factors such as age and smoking. Prevalence odds ratios (OR) and 95\% confidence intervals (95\% CI) were obtained from the estimated logistic regression coefficients and their standard errors. The measures of vibration dose entered the logistic models as either quintile based design variables or continuous covariates. Age and smoking were included in the models as continuous and dichotomous covariates, respectively. Interaction between independent variables was assessed by the inclusion of appropriate product terms.

When the outcome was given by the score of finger blanching, severity was treated as an ordinal scale response variable ( score 0, no blanching; score 1-8, mild blanching; score 9-20, moderate blanching; score $\geqslant 21$, severe blanching); ordinal logistic regression models were used to assess the association between the severity of VWF and alternative measures of vibration dose. Since an approximate likelihood ratio test showed that the proportional odds assumption for cumulative logit models (that is, the effects of the explanatory variables 
Table 3 Prevalence of VWF and distribution of finger blanching score in the vibration exposed worker groups

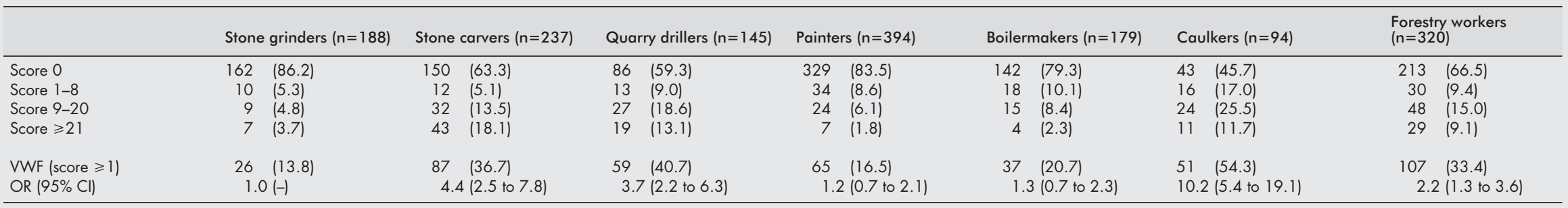

Results expressed as number (percentage). Age and smoking adjusted odds ratios (OR) and $95 \%$ confidence intervals $(95 \% \mathrm{Cl}$ ) for VWF among the vibration exposed groups (reference category: stone grinders) were obtained from logistic regression analysis.

Table 4 Age and smoking adjusted estimates of the odds ratio (OR) and $95 \%$ confidence interval (95\% CI) for the association between VWF and measures of vibration exposure expressed in terms of total equivalent r.m.s. acceleration (frequency-weighted: $a_{h, w e q, T)}$ unweighted: $a_{h, w e q, T)}$ ), and lifetime duration of exposure (total operating hours or years of exposure)

\begin{tabular}{|c|c|c|c|c|c|c|c|c|}
\hline \multirow[b]{2}{*}{ Models } & & \multicolumn{5}{|c|}{ Quintiles of measures of vibration exposure } & \multirow{2}{*}{$\begin{array}{l}\text { LR test } \\
\left(\chi^{2}, 4 \mathrm{dft}\right)\end{array}$} & \multirow{2}{*}{$\begin{array}{l}\text { H-L test } \\
\left(\chi^{2}, 8 \mathrm{dft}\right)\end{array}$} \\
\hline & & 1 st & 2nd & 3 rd & 4 th & 5 th & & \\
\hline \multicolumn{9}{|l|}{ Model 1: } \\
\hline$a_{h, w l e q, T}\left(m s^{-2}\right)$ & midpoint & 2.6 & 5.1 & 7.1 & 17.0 & 20.7 & & \multirow{4}{*}{${ }^{6.55}(p=0.59)$} \\
\hline OR $(95 \%$ CI) & & $1.0(-)$ & 4.7 (2.9 to 7.6$)$ & 3.6 (2.3 to 5.7 ) & $3.9(2.5$ to 6.1$)$ & 3.5 (2.2 to 5.8$)$ & $60.2^{*}$ & \\
\hline Total operating time (h) & midpoint & 900 & 3100 & 6800 & 15000 & 37500 & & \\
\hline $\begin{array}{l}\text { OR }(95 \% \mathrm{CI}) \\
\text { Model } 2:\end{array}$ & & $1.0(-)$ & 2.2 (1.3 to 3.8 ) & 2.2 (1.3 to 3.7 ) & 5.5 (3.3 to 9.1$)$ & 9.7 (5.6 to 16.7) & $111.2^{*}$ & \\
\hline $\begin{array}{l}a_{\text {h.uwleq, }}\left(\mathrm{ms}^{-2}\right) \\
O R(95 \% \mathrm{Cl})\end{array}$ & midpoint & $\begin{array}{l}34.3 \\
1.0(-)\end{array}$ & $\begin{array}{l}49.2 \\
4.9(3.0 \text { to } 7.9)\end{array}$ & $\begin{array}{l}62.7 \\
3.7 \text { (2.3 to } 5.8 \text { ) }\end{array}$ & $\begin{array}{l}97.7 \\
4.3 \text { (2.8 to } 6.8 \text { ) }\end{array}$ & $\begin{array}{l}120 \\
3.3(2.0 \text { to } 5.3)\end{array}$ & $65.2^{*}$ & \multirow{2}{*}{${ }^{4.51}(p=0.81)$} \\
\hline $\begin{array}{l}\text { Total operating time (h) } \\
\text { OR }(95 \% \mathrm{Cl})\end{array}$ & midpoint & $\begin{array}{l}900 \\
1.0(-)\end{array}$ & $\begin{array}{l}3100 \\
2.2(1.3 \text { to } 3.6)\end{array}$ & $\begin{array}{l}6800 \\
2.2(1.3 \text { to } 3.7)\end{array}$ & $\begin{array}{l}15000 \\
5.5(3.3 \text { to } 9.2)\end{array}$ & $\begin{array}{l}37500 \\
9.5(5.5 \text { to } 16.3)\end{array}$ & $106.2^{*}$ & \\
\hline \multicolumn{9}{|l|}{ Model 3: } \\
\hline$a_{h, w e q, T}\left(m s^{-2}\right)$ & midpoint & 2.6 & 5.1 & & 17.0 & 20.7 & & \multirow{5}{*}{$16.8 \quad(p=0.03)$} \\
\hline OR $(95 \% \mathrm{Cl})$ & & $1.0(-)$ & 3.7 (2.4 to 5.9 ) & 3.8 (2.4 to 5.9 ) & 4.0 (2.5 to 6.2$)$ & 2.5 (1.6 to 4.0 ) & $56.6^{*}$ & \\
\hline Years of exposure $(y)$ & midpoint & 3 & 7 & 12 & 21 & 33 & & \\
\hline OR $(95 \% \mathrm{Cl})$ & & $1.0(-)$ & 2.7 (1.6 to 4.6$)$ & $3.2(1.9$ to 5.4$)$ & $4.6(2.7$ to 7.8$)$ & $7.1(4.0$ to 12.6$)$ & $53.1^{*}$ & \\
\hline \multirow{2}{*}{\multicolumn{9}{|c|}{ Model 4: }} \\
\hline & & & & & & & & \\
\hline OR $(95 \% \mathrm{Cl})$ & & $1.0(-)$ & 4.0 (2.5 to 6.4 ) & $3.9(2.5$ to 6.1$)$ & 4.5 (2.9 to 7.0$)$ & $2.3(1.4$ to 3.6$)$ & $66.8^{*}$ & \multirow{3}{*}{$19.0 \quad(p=0.02)$} \\
\hline Years of exposure (y) & midpoint & & 7 & 12 & 21 & 33 & & \\
\hline OR $(95 \% \mathrm{Cl})$ & & $1.0(-)$ & 2.7 (1.6 to 4.6$)$ & 3.3 (1.9 to 5.5 ) & 4.7 (2.7 to 8.1$)$ & 7.3 (4.1 to 13.1$)$ & $53.2^{*}$ & \\
\hline
\end{tabular}


Table 5 Age and smoking adjusted estimates of the odds ratio (OR) and $95 \%$ confidence interval $(95 \% \mathrm{Cl})$ for the association between VWF and alternative measures of vibration dose in the total sample of vibration exposed workers $(n=1557)$

\begin{tabular}{|c|c|c|c|c|c|c|c|c|}
\hline \multirow[b]{2}{*}{ Dose definition } & & \multicolumn{5}{|c|}{ Quintiles of vibration dose } & \multirow{2}{*}{$\begin{array}{l}\text { LR test } \\
\left(\chi^{2}, 4 \mathrm{dft}\right)\end{array}$} & \multirow{2}{*}{$\begin{array}{l}\text { H-L test } \\
\left(\chi^{2}, 8 \mathrm{dft}\right)\end{array}$} \\
\hline & & $1 \mathrm{st}$ & 2nd & $3 r d$ & 4 th & 5 th & & \\
\hline$\Sigma \mathrm{t}_{\mathrm{i}}$ (hours) $\left(\times 10^{2}\right)$ & midpoint & 9 & 31 & 68 & 150 & 375 & & \\
\hline VWF $(\%)$ & & 8.0 & 17.0 & 20.0 & 37.2 & 55.6 & 94.1 * & 11.8 \\
\hline OR $(95 \% \mathrm{CI})$ & & $1.0(-)$ & $2.2(1.3$ to 3.6$)$ & $2.2(1.3$ to 3.6$)$ & $4.6(2.8$ to 7.6$)$ & 7.2 (4.4 to 11.9 ) & & $1 p=0.16$ \\
\hline$\Sigma \mathrm{a}_{\mathrm{wi}} \mathrm{t}_{\mathrm{i}}\left(\mathrm{ms}^{-2} \mathrm{~h}\right)\left(\times 10^{3}\right)$ & midpoint & 6.5 & 23 & 50 & 127 & 415 & & \\
\hline VWF (\%) & & 10.0 & 15.1 & 22.5 & 33.0 & 58.2 & $106.2 *$ & 4.3 \\
\hline OR $(95 \% \mathrm{CI})$ & & $1.0(-)$ & 1.2 (0.7 to 2.0$)$ & $2.0(1.2$ to 3.1$)$ & 2.9 (1.9 to 4.7$)$ & 6.6 (4.1 to 10.5$)$ & & $1 p=0.83$ \\
\hline$\Sigma a_{w i}{ }^{2} t_{i}\left(m^{2} s^{-4} h\right)\left(\times 10^{4}\right)$ & midpoint & 4 & 14.5 & 42.5 & 183 & 735 & & \\
\hline VWF (\%) & & 10.3 & 21.2 & 26.4 & 29.2 & 51.8 & $65.3^{*}$ & 3.6 \\
\hline OR $(95 \% \mathrm{Cl})$ & & $1.0(-)$ & 1.7 (1.1 to 2.8$)$ & $2.3(1.4$ to 3.6$)$ & $2.9(1.8$ to 4.5$)$ & $5.0(3.1$ to 7.8$)$ & & $1 p=0.89$ \\
\hline$\Sigma a_{w i}{ }^{4} t_{i}\left(m^{4} s^{-8} h\right)\left(\times 10^{6}\right)$ & midpoint & 1 & 6 & 71.5 & 661 & 3686 & & \\
\hline VWF (\%) & & 11.9 & 26.4 & 29.3 & 26.3 & 45.0 & $46.5^{*}$ & 6.8 \\
\hline OR $(95 \% \mathrm{Cl})$ & & $1.0(-)$ & 1.9 (1.2 to 3.0$)$ & 2.7 (1.8 to 4.3$)$ & 2.6 (1.7 to 4.2$)$ & 3.8 (2.5 to 5.9$)$ & & $1 p=0.56$ \\
\hline$\Sigma a_{u w i} t_{i}\left(m^{-2} h\right)\left(\times 10^{4}\right)$ & midpoint & 5.5 & 19 & 41.5 & 92.5 & 256 & & \\
\hline VWF $(\%)$ & & 8.7 & 14.4 & 23.2 & 32.4 & 60.1 & 115.1 * & 4.4 \\
\hline OR $(95 \% \mathrm{CI})$ & & $1.0(-)$ & 1.4 (0.9 to 2.4$)$ & 2.4 (1.5 to 3.9$)$ & 3.4 (2.1 to 5.5$)$ & 8.4 (5.1 to 13.8 ) & & $1 p=0.78$ \\
\hline$\Sigma a_{u w i}{ }^{2} t_{i}\left(m^{2} s^{-4} h\right)\left(\times 10^{6}\right)$ & midpoint & 3 & 11.5 & 27.5 & 75.5 & 249 & & \\
\hline VWF (\%) & & 10.3 & 16.8 & 23.3 & 29.4 & 59.0 & $100.2^{*}$ & 5.6 \\
\hline OR $(95 \% \mathrm{CI})$ & & $1.0(-)$ & 1.4 (0.9 to 2.3$)$ & 2.0 (1.2 to 3.2$)$ & 2.6 (1.6 to 4.0 ) & 6.5 (4.1 to 10.3$)$ & & $1 p=0.69$ \\
\hline$\sum \mathrm{a}_{\mathrm{uwi}}{ }^{4} \mathrm{t}_{\mathrm{i}}\left(\mathrm{m}^{4} \mathrm{~s}^{-8} \mathrm{~h}\right)\left(\times 10^{10}\right)$ & midpoint & 1 & 4.5 & 18 & 77 & 274 & & \\
\hline VWF $(\%)$ & & 12.9 & 24.6 & 18.0 & 27.2 & 56.0 & $72.8^{*}$ & 7.9 \\
\hline OR $(95 \% \mathrm{Cl})$ & & $1.0(-)$ & $1.6(1.0$ to 2.5$)$ & $1.3(0.8$ to 2.1$)$ & 2.3 (1.5 to 3.5$)$ & 4.6 (3.0 to 7.1$)$ & & I $p=0.44$ \\
\hline
\end{tabular}

In the logistic regression models, vibration dose was included as a quintile based design variable, assuming the lowest quintile as the reference category.

The prevalence of VWF in each quintile of vibration dose is shown. The likelihood ratio (LR) test for the measures of vibration dose, and the

Hosmer-Lemeshow $(\mathrm{H}-\mathrm{L})$ test for the goodness of fit of the logistic models are given.

$\mathrm{a}_{\mathrm{w}}=$ frequency-weighted acceleration; $\mathrm{a}_{\mathrm{uw}}=$ unweighted acceleration; $t=$ total operating time

${ }^{*} \mathrm{p}<0.001, \dagger d f=$ degrees of freedom.

on the cumulative response probabilities are constant across all categories of the ordinal response) was violated, a generalised ordered logit regression model was fitted to the data (program gologit in Stata). This model relaxes the restrictive proportional odds assumption. Assuming an ordinal dependent variable takes on the values $0,1,2, \ldots, k$, the generalised ordered logit model allows the effects of the explanatory variables to vary with each of the $k-1$ points at which the dependent variable is dichotomised..$^{18}$ The model estimates a set of regression coefficients that correspond to the possible cumulative binary logits that can be formed from the categories of the dependent variable.

The significance of additional variables in the logistic model was assessed by the likelihood ratio $\chi^{2}$ test. The magnitude of the likelihood ratio statistic was used to assess the "importance", in statistical terms, of the alternative measures of vibration dose for the prediction of the outcome. The Bayesan information criterion was also used to compare the fit of nonnested logistic models (program fitstat in Stata). ${ }^{19}$ The goodness of fit of the logistic models was assessed by the Hosmer-Lemeshow $\chi^{2}$ statistic. $^{20}$

\section{RESULTS}

\section{VWF symptoms in the study groups}

Table 3 shows the prevalence of VWF and the distribution of the scores of finger blanching severity in the vibration exposed groups. Taking the occupational group with the lowest prevalence of VWF as the reference category (stone grinders, VWF $13.8 \%)$, significantly increased age adjusted and smoking adjusted ORs for VWF were observed for the stone carvers (OR $4.4,95 \%$ CI 2.5 to 7.8 ), quarry drillers (OR 3.7, 95\% CI 2.2 to 6.3), dockyard caulkers (OR 10.2, 95\% CI 5.5 to 19.1), and forestry workers (OR 2.2, 95\% CI 1.3 to 3.6 ). These occupational groups also showed a greater probability of severe symptoms of VWF (blanching score $\geqslant 21$ ) than the stone grinders, dockyard boilermakers, and dockyard painters.

\section{Relation between VWF symptoms and exposure variables}

To assess the separate effects of vibration magnitude and exposure duration on the probability of the occurrence of VWF, four different logistic regression models were fitted to the data. In addition to age and smoking, each of the logistic models included two measures of vibration exposure: a measure of vibration magnitude (in terms of either $a_{\text {h.w(eq,T) }}$ or $a_{\mathrm{h}, \mathrm{uw}(\mathrm{eq}, T)}$ ) and a measure of exposure duration (in terms of either total operating hours or years of exposure). These measures of vibration exposure were included in the logistic models as quintile based design variables, assuming the lowest quintile as the reference category (table 4). Each quintile included approximately 300 individuals. Within each of the models in table 4, each measure of vibration exposure (magnitude or duration) has been adjusted for the effect of the other measure (duration or magnitude). The likelihood ratio test showed that both vibration magnitude and exposure duration were significant predictors of VWF probability, although to differing degrees. The contribution of total operating hours to the prediction of VWF was greater $\left(\chi^{2}=106,4 \mathrm{df}\right.$ (with $\mathrm{a}_{\mathrm{h} \text {,uwieq, } \mathrm{T})}$ included in the model); $\chi^{2}=111$, $4 \mathrm{df}$ (with $\mathrm{a}_{\mathrm{hw}(\mathrm{seq})}$ included in the model)) than that of years of exposure $\left(\chi^{2}=53,4 \mathrm{df}\right.$ (with either $\mathrm{a}_{\mathrm{h}, \text { uw (eq, T) }}$ or $\mathrm{a}_{\mathrm{h}, \mathrm{w}(\mathrm{eq}, \mathrm{T})}$ included in the model)). Vibration acceleration magnitude also contributed significantly to the various models, with a small improvement for those models that included unweighted acceleration magnitude compared with those containing frequency-weighted acceleration magnitude. Similar results were obtained when the measures of vibration exposure were included in the logistic models as continuous independent variables (results not shown). When the observed frequencies of the outcome variable (VWF) were compared with those predicted by the different models according to a grouping method based on deciles of risk ${ }^{20}$ the Hosmer-Lemeshow goodness-of-fit statistic suggested that the logistic models that included acceleration magnitude $\left(a_{\text {h,wee, } T \text { or }}\right.$ or $\left.a_{\text {h.uw(eq,T) }}\right)$ and total operating hours as measures of vibration exposure 


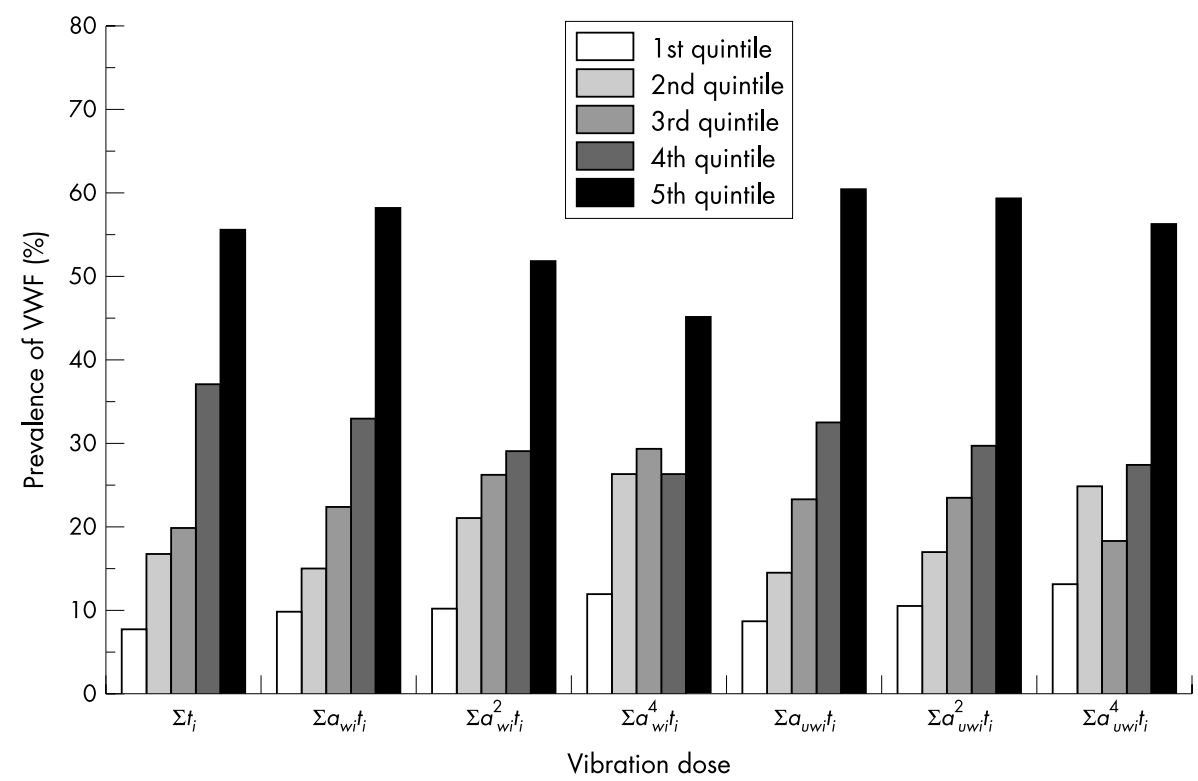

Figure 1 Prevalence of VWF in the total sample of 1557 vibration exposed workers by quintiles of alternative measures of lifetime vibration dose. The various measures of vibration dose were estimated as the total lifetime duration of exposure $(t$, in $h)$ alone or in combination with the frequency-weighted $\left(a_{\text {wir }}\right.$ in $\left.\mathrm{ms}^{-2}\right)$ or the unweighted $\left(a_{u w i}\right.$ in $\left.\mathrm{ms}^{-2}\right)$ acceleration magnitude of vibration produced by the hand held tools used by the workers (see table 5).

performed substantially better $\left(\chi^{2}=4.5\right.$ and $\left.6.6,8 \mathrm{df}\right)$ than those including acceleration magnitude and years of exposure $\left(\chi^{2}=16.8\right.$ and $\left.19.0,8 \mathrm{df}\right)$.

In table 4, each measure of vibration exposure (magnitude or duration) has been adjusted for the effect of the other measure (duration or magnitude). The LR statistics values for

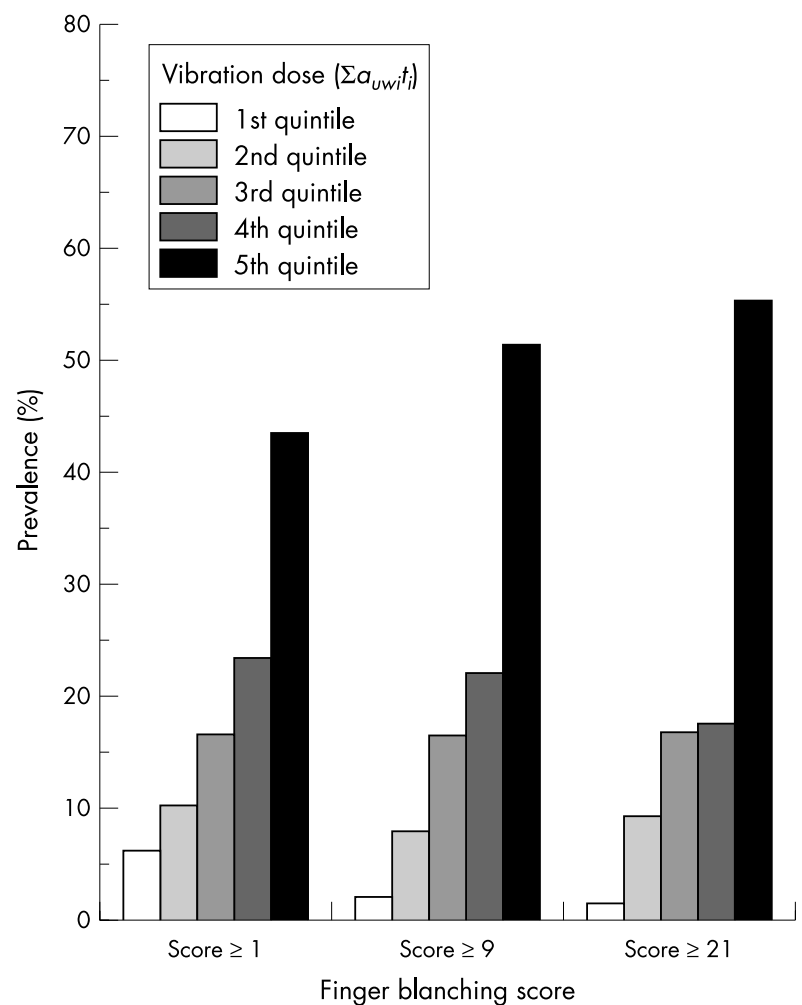

Figure 2 Crude prevalence of increasing scores of finger blanching severity by quintiles of vibration dose of the form $\Sigma a_{u v i} t_{i}$ $\left(\mathrm{ms}^{-2} \mathrm{~h}\right.$, unweighted acceleration). Cumulative prevalence adds up to $100 \%$ within each category of finger blanching score. Values apply at the time of the examination. fitting together equivalent acceleration and exposure duration were: model 1 , LR $=154.2$; model 2, LR $=159.2$; model 3, $\mathrm{LR}=96.1$; model 4 , $\mathrm{LR}=106.3$ (all with 8 degrees of freedom, $\mathrm{p}<0.001$ ).

\section{Alternative measures of vibration dose for predicting symptoms}

For all seven measures of vibration dose computed from acceleration magnitude $\left(a_{\mathrm{wi}}\right.$ or $\left.a_{\text {uwi }}\right)$ and lifetime exposure duration (total operating hours), an increase in dose was generally associated with an increase in the prevalence of VWF (fig l). The results of logistic regression analysis confirmed the association between VWF and the seven alternative measures of vibration dose. Assuming the lowest quintile of vibration dose as the reference category, age adjusted and smoking adjusted ORs for VWF showed a pattern of increased risk with increased estimated doses (table 5).

The strength of the relation between the alternative measures of dose and the occurrence of VWF varied between dose measures. Generally, dose measures with high powers of acceleration (i.e. $m>1$ ) faired less well than measures in which the acceleration, $a_{\mathrm{wi}}$ or $a_{\mathrm{uwi},}$ and lifetime exposure duration, $t$, were given equal weight. Indeed, dose determined solely by the duration of exposure (without consideration of the vibration magnitude) tended to give better predictions than measures with values of $m$ greater than unity, with the exception for $\Sigma a_{\mathrm{uwi}}{ }^{2} t_{\mathrm{i}}\left(\mathrm{m}^{2} \mathrm{~s}^{-4} \mathrm{~h}\right.$, unweighted acceleration). The magnitude of the likelihood ratio statistic suggested that all measures of dose were stronger predictors of VWF when the dose was calculated from the unweighted acceleration than from the frequency-weighted acceleration. Similar results were obtained when the measures of vibration dose were included in the logistic models as continuous covariates (results not shown).

In all of the logistic models, VWF was found to be associated with age and smoking. For instance, in the logistic model including vibration dose of the form $\Sigma a_{\text {uwi }} t_{i}\left(\mathrm{~ms}^{-2} \mathrm{~h}\right.$, unweighted acceleration), the estimated OR for an increase of 10 years in age was 1.5 (95\% CI 1.3 to 1.7 ) and the OR for smoking was 1.6 (95\% CI 1.2 to 2.1 ). There was no evidence of significant interactions between age, smoking, and alternative measures of vibration dose when product terms involving these variables were added to the logistic models. 
Table 6 Age and smoking adjusted estimates of the odds ratio (OR) and $95 \%$ confidence interval $(95 \% \mathrm{Cl})$ for the association between the severity of VWF and alternative measures of vibration dose in the total sample of vibration exposed workers $(n=1557)$

\begin{tabular}{|c|c|c|c|c|c|c|c|}
\hline \multirow[b]{2}{*}{ Dose definition } & \multicolumn{6}{|c|}{ Quintiles of vibration dose } & \multirow{2}{*}{$\begin{array}{l}- \text { LR test } \\
\left(\chi^{2}, 12 \mathrm{dft}\right)\end{array}$} \\
\hline & & $1 \mathrm{st}$ & 2nd & $3 r d$ & 4th & 5 th & \\
\hline$\Sigma \mathrm{t}_{\mathrm{i}}$ (hours) $\left(\times 10^{2}\right)$ & midpoint & 9 & 31 & 68 & 150 & 375 & \\
\hline Score $\geqslant 1$ & \multirow[t]{3}{*}{ OR $(95 \% \mathrm{CI})$} & $1.0(-)$ & $2.2(1.3$ to 3.6$)$ & $2.2(1.3$ to 3.6$)$ & $4.6 \quad(2.8$ to 7.4$)$ & 7.2 (4.4 to 11.9$)$ & \\
\hline Score $\geqslant 9$ & & $1.0(-)$ & 7.7 (2.7 to 22.2$)$ & 9.1 (3.2 to 26.0 ) & 17.1 (6.1 to 47.8$)$ & 32.9 (11.7 to 92.1$)$ & \\
\hline Score $\geqslant 21$ & & $1.0(-)$ & 6.0 (1.4 to 25.9 ) & 6.1 (1.4 to 26.2$)$ & 8.2 (2.0 to 34.3$)$ & 24.1 (5.9 to 98.7$)$ & 138.9 * \\
\hline$\Sigma \mathrm{a}_{\mathrm{wi}} \mathrm{t}_{\mathrm{i}}\left(\mathrm{ms}^{-2} \mathrm{~h}\right)\left(\times 10^{3}\right)$ & midpoint & 6.5 & 23 & 50 & 127 & 415 & \\
\hline Score $\geqslant 1$ & \multirow[t]{3}{*}{ OR $(95 \% \mathrm{CI})$} & $1.0(-)$ & $1.2(0.8$ to 2.0$)$ & 2.0 (1.2 to 3.1$)$ & $3.0 \quad(1.9$ to 4.7$)$ & 6.5 (4.1 to 10.4$)$ & \\
\hline Score $\geqslant 9$ & & $1.0(-)$ & $3.0(1.4$ to 6.5$)$ & 3.5 (1.7 to 7.5$)$ & 6.9 (3.4 to 14.3 ) & $15.0(7.3$ to 30.8$)$ & \\
\hline Score $\geqslant 21$ & & $1.0(-)$ & 4.1 (1.2 to 14.3$)$ & 4.0 (1.1 to 13.9$)$ & $5.8 \quad(1.7$ to 19.6$)$ & 15.1 (4.6 to 49.2 ) & $139.5^{*}$ \\
\hline$\Sigma a_{w i}{ }^{2} t_{i}\left(m^{2} s^{-4} h\right)\left(\times 10^{4}\right)$ & midpoint & 4 & 14.5 & 42.5 & 183 & 735 & \\
\hline Score $\geqslant 1$ & \multirow[t]{3}{*}{ OR $(95 \% \mathrm{Cl})$} & $1.0(-)$ & 1.7 (1.1 to 2.8$)$ & 2.3 (1.4 to 3.6$)$ & $2.9 \quad(1.8$ to 4.5$)$ & 4.9 (3.1 to 7.7$)$ & \\
\hline Score $\geqslant 9$ & & $1.0(-)$ & $2.9(1.5$ to 5.7$)$ & 3.7 (1.9 to 7.2$)$ & $4.7 \quad(2.5$ to 9.1$)$ & $9.1 \quad(4.8$ to 17.2$)$ & \\
\hline Score $\geqslant 21$ & & $1.0(-)$ & $2.5(1.0$ to 6.5$)$ & $2.2(0.8$ to 5.7$)$ & $3.2 \quad(1.3$ to 8.0$)$ & $6.8(2.8$ to 16.6$)$ & $86.4^{*}$ \\
\hline$\sum a_{w i}{ }^{4} t_{i}\left(m^{4} s^{-8} h\right)\left(\times 10^{6}\right)$ & midpoint & 1 & 6 & 71.5 & 661 & 3686 & \\
\hline Score $\geqslant 1$ & \multirow[t]{3}{*}{ OR $(95 \% \mathrm{Cl})$} & $1.0(-)$ & 1.9 (1.2 to 3.0 ) & 2.7 (1.8 to 4.3 ) & $2.6 \quad(1.7$ to 4.1$)$ & 3.8 (2.5 to 5.8$)$ & \\
\hline Score $\geqslant 9$ & & $1.0(-)$ & 2.4 (1.4 to 4.3 ) & 2.8 (1.6 to 4.9 ) & $3.3 \quad(1.9$ to 5.8$)$ & $4.9(2.8$ to 8.3$)$ & \\
\hline Score $\geqslant 21$ & & $1.0(-)$ & $1.3(0.6$ to 2.8$)$ & 1.2 (0.5 to 2.5 ) & $1.8 \quad(0.9$ to 3.9$)$ & $2.9 \quad(1.5$ to 5.7$)$ & $62.7^{*}$ \\
\hline$\Sigma a_{u w i} t_{i}\left(m s^{-2} h\right)\left(\times 10^{4}\right)$ & midpoint & 5.5 & 19 & 41.5 & 92.5 & 256 & \\
\hline Score $\geqslant 1$ & \multirow[t]{3}{*}{$\operatorname{OR}(95 \% \mathrm{Cl})$} & $1.0(-)$ & 1.4 (0.9 to 2.4$)$ & 2.4 (1.5 to 4.0 ) & $3.4(2.1$ to 5.4$)$ & $8.2 \quad(5.0$ to 13.4$)$ & \\
\hline Score $\geqslant 9$ & & $1.0(-)$ & $3.0(1.3$ to 7.2$)$ & 6.1 (2.7 to 13.9$)$ & $7.7 \quad(3.4$ to 17.3$)$ & $21.8(9.8$ to 48.7$)$ & \\
\hline Score $\geqslant 21$ & & $1.0(-)$ & 4.7 (1.0 to 21.5$)$ & 8.4 (1.9 to 36.2 ) & 7.6 (1.8 to 32.6$)$ & 24.3 (5.8 to 101$)$ & $149.6 *$ \\
\hline$\sum \mathrm{a}_{\mathrm{uwi}}{ }^{2} \mathrm{t}_{\mathrm{i}}\left(\mathrm{m}^{2} \mathrm{~s}^{-4} \mathrm{~h}\right)\left(\times 10^{6}\right)$ & midpoint & 3 & 11.5 & 27.5 & 75.5 & 249 & \\
\hline Score $\geqslant 1$ & \multirow[t]{3}{*}{ OR $(95 \% \mathrm{CI})$} & $1.0(-)$ & $1.4(0.8$ to 2.2$)$ & $2.0(1.3$ to 3.2$)$ & 2.5 (1.6 to 4.0$)$ & 6.4 (4.0 to 10.2$)$ & \\
\hline Score $\geqslant 9$ & & $1.0(-)$ & $2.4(1.2$ to 4.9$)$ & $3.1 \quad(1.6$ to 6.0$)$ & $4.3(2.3$ to 8.3$)$ & 10.6 (5.6 to 20.2$)$ & \\
\hline Score $\geqslant 21$ & & $1.0(-)$ & $1.7(0.6$ to 4.8$)$ & 3.0 (1.2 to 7.7$)$ & $2.3(0.9$ to 6.0$)$ & $7.7 \quad(3.2$ to 18.8$)$ & $121.3^{*}$ \\
\hline$\sum \mathrm{a}_{\mathrm{uwi}}{ }^{4} \mathrm{t}_{\mathrm{i}}\left(\mathrm{m}^{4} \mathrm{~s}^{-8} \mathrm{~h}\right)\left(\times 10^{10}\right)$ & midpoint & 1 & 4.5 & 18 & 77 & 274 & \\
\hline Score $\geqslant 1$ & \multirow[t]{3}{*}{ OR $(95 \% \mathrm{Cl})$} & $1.0(-)$ & $1.6(1.0$ to 2.5$)$ & $1.3(0.8$ to 2.1$)$ & $2.3 \quad(1.5$ to 3.5$)$ & $4.6 \quad(3.0$ to 7.0$)$ & \\
\hline Score $\geqslant 9$ & & $1.0(-)$ & 2.1 (1.2 to 3.7$)$ & $1.6(0.9$ to 2.9$)$ & 2.6 (1.5 to 4.5$)$ & 5.7 (3.4 to 9.8$)$ & \\
\hline Score $\geqslant 21$ & & $1.0(-)$ & $1.7(0.8$ to 3.7$)$ & $1.3(0.5$ to 3.0$)$ & $1.8 \quad(0.8$ to 3.9$)$ & $4.1 \quad(2.0$ to 8.5$)$ & $84.1^{*}$ \\
\hline $\begin{array}{l}\text { Values apply at the tim } \\
\text { blanching, score } 1-8, \text { s } \\
\geqslant 1 \text {, score } \geqslant 9 \text {, score } \geqslant \\
\text { lowest quintile as the re } \\
{ }^{*} p<0.001 \text {, } \dagger d f=\text { degre }\end{array}$ & $\begin{array}{l}\text { 9-20, scor } \\
\text { In the orde } \\
\text { ce categor } \\
\text { freedom. }\end{array}$ & $\begin{array}{l}\text { 1). Th } \\
\text { gistic } \\
\text { likel }\end{array}$ & $\begin{array}{l}\text { come was dichote } \\
\text { ssion models, vib } \\
\text { ratio (LR) test for }\end{array}$ & $\begin{array}{l}\text { mised taking accou } \\
\text { ration dose was inc } \\
\text { he measures of vibr }\end{array}$ & $\begin{array}{l}\text { ling to a score of fing } \\
\text { t of the ordering by } \\
\text { uded as a quintile bas } \\
\text { ation dose is shown. }\end{array}$ & $\begin{array}{l}\text { blanching severity } \\
\text { ng cumulative prob } \\
\text { design variable, }\end{array}$ & $\begin{array}{l}\text { ore } 0=\text { no } \\
\text { lities (score } \\
\text { uming the }\end{array}$ \\
\hline
\end{tabular}

The measures of vibration dose were found to be associated not only with VWF as a binary outcome (that is, whether or not finger blanching was present) but also with the severity of VWF (using the blanching score ${ }^{915}$ to place subjects in one of four bands) treated as an ordinal response variable. As an example, fig 2 shows the crude prevalence of increasing scores of finger blanching severity according to quintiles of vibration dose $\left(\Sigma a_{\text {uvi }} t_{i}\right)$.

When finger blanching score was dichotomised by using cumulative probabilities (score $\geqslant 1$, score $\geqslant 9$, score $\geqslant 21$ ), the estimated generalised ordered logit models showed significant age adjusted and smoking adjusted associations between the severity of VWF and all of the alternative measures of vibration dose (table 6). Using a separate binary regression approach, the Hosmer-Lemeshow summary goodness-of-fit statistic indicated good overall fit for each of the individual logistic regression models $\left(\chi^{2} 1.1\right.$ to $\left.11.9,8 \mathrm{df}\right)$. Similar to the findings of the ordinary binary logistic models, dose measures with powers of acceleration equal to unity, as well as doses calculated from the unweighted acceleration, seem to contribute better to the fit of the models than those with powers of acceleration greater than unity and those derived solely from the frequency-weighted acceleration, respectively. The values of the likelihood ratio test suggest that the logit models which included vibration doses with powers of acceleration (either $a_{\mathrm{wi}}$ or $a_{\mathrm{uwi}}$ ) greater than unity provide no advantage as compared with the more simple model using total exposure duration alone.

The effect of smoking on the severity of VWF was also investigated. In the model with age and $\Sigma a_{\text {uwi }} t_{i}$ the ORs $(95 \%$ CI) for smoking were: 1.56 ( 1.21 to 2.00$)$ for VWF score $\geqslant 1$, 1.42 ( 1.07 to 1.88 ) for VWF score $\geqslant 9$, and 1.80 ( 1.21 to 2.68 ) for VWF score $\geqslant 21$. A test for trend showed no significant dif- ference between the three OR values. Identical results (that is, no significant trend for the ORs for smoking) were obtained with models including the other measures of vibration dose and age.

\section{DISCUSSION}

It was suggested above that a dose-response model for VWF should include quantifiable independent variables known to have a large influence on finger blanching, that there should be a positive correlation between the model predictions and the outcome found in practice, and that the accuracy of the predictions of the outcome should be quantified. In this study, vibration magnitudes and lifetime exposure durations were combined in seven different ways to produce lifetime measures of "dose" for predicting the prevalence and severity of VWF in the studied populations, taking into account any effects of age and smoking.

\section{Subject characteristics}

In this study, age was a significant predictor of the occurrence of white finger and this is consistent with the findings of some previous epidemiological investigations. ${ }^{21}{ }^{22}$ As expected, age was a confounder of the association between digital vascular symptoms and vibration exposure (that is, age was linked both to VWF and to the measures of vibration dose). Smoking was also significantly associated with the onset of finger blanching, but its confounding effect was minimal because the crude OR estimates for vibration exposure reduced very little after adjustment for smoking, from 3\% to $7 \%$. In this study, neither age nor smoking seemed to have acted as effect modifying variables: logistic regression analysis showed that there were no interactions of these variables and the various measures of vibration dose in producing VWF. 


\section{Effects of exposure variables}

The consequences of exposures to hand-transmitted vibration are widely assumed to depend on the frequency of vibration, the exposure duration, and the vibration magnitude. In addition, it may be expected that the direction of vibration and hand-to-tool contact forces may have an effect.

\section{Frequency weighting}

Dose measures derived from frequency-weighted acceleration according to current standards (that is, using frequency weighting $W_{\mathrm{h}}$ ) produced less good predictions of finger blanching than equivalent doses calculated from unweighted acceleration. The $W_{\mathrm{h}}$ frequency weighting in International Standard 5349 assumes that vibration has an effect that depends on vibration velocity, between 16 and $1000 \mathrm{~Hz}$ (that is, the acceleration weighting decreases in inverse proportion to frequency). Finding that the unweighted acceleration provides a better prediction of blanching suggests that the effect depends more closely on acceleration, but the frequency range over which this applies is restricted to the range of frequencies for which the tools studied had their most dominant components. There was not an epidemiological, pathological, or physiological basis for the selection of the $W_{\mathrm{h}}$ characteristic for predicting VWF in ISO 5349'; unweighted acceleration has been previously suggested for evaluating the severity of handtransmitted vibration. ${ }^{23}$ While the present results indicate that the use of frequency weighting $W_{\mathrm{h}}$ is not optimum for the prediction of VWF, it should be recognised that finger blanching is not the only adverse effect of hand-transmitted vibration and that the various disorders may have different frequency dependence: some may be better predicted by using weighting $W_{\mathrm{h}}$ than unweighted acceleration. Furthermore, the frequency range over which unweighted acceleration may be used to predict finger blanching is not known.

\section{Time dependency}

Although the seven dose models used four different time dependencies (dose $=\Sigma a_{i}^{m} t_{i}$, where $m=0,1,2$, or 4 ) the vibration magnitudes for all tools were represented by root-meansquare acceleration: the second power relation was assumed so as to obtain average measures of tool vibration magnitudes (that is, root-mean-square acceleration was measured). Different averaging procedures during vibration measurement might have changed the relative severity of vibration on different tools, depending on the impulsiveness of the vibration. For example, fourth power (or root-mean-quad) averaging would have increased the magnitudes on percussive tools, such as chipping hammers and stone working hammers, relative to the rotary tools, such as grinders and drilling machines. This might have affected the relative performance of the seven dose models, and so the current findings are restricted to situations where the vibration magnitude is expressed in terms of r.m.s. acceleration.

International Standard $5349\left(1986,{ }^{1} 2001^{16}\right)$ assumes a second power time dependency during the day, and daily exposure to hand-transmitted vibration is represented by an "energy equivalent" vibration magnitude, the r.m.s. acceleration normalised to a reference period (four hours in ISO 5349, 1986'; eight hours in ISO 5349-1, 2001 ${ }^{16}$ ). In an informative annex, ISO 5349 suggests an almost linear relation between this daily "energy equivalent" acceleration and the number of years of exposure for equal probability of developing VWF (e.g. $a_{\mathrm{hw}(\mathrm{eq}, \text { sh) }} /$ years $=$ constant).

In the present study, no distinction was made between the accumulation of exposure duration during the working day and the accumulation of exposure over days, months and years (that is, lifetime exposure). However, the total duration of exposure expressed in hours was found to be a better predictor of finger blanching than years of exposure (that is, years in the job). It might be argued that without evidence of a need for different time dependencies for daily and lifetime exposures, the additional complexity of having two time dependencies is unjustified. In this study, a single simple measure of the total duration of exposure to hazardous vibration provided a good indication of risk. Refining this dose, by including vibration magnitude, only improved the predictive power of the dose when a linear relation between total exposure and acceleration magnitude was used (i.e. $m=1$; dose $=$ $\Sigma a_{\text {uwi }} t_{\mathrm{i}}$ ). Other combinations of acceleration magnitude and total exposure duration degraded the power of predicting the development of finger blanching relative to that achieved with cumulative exposure duration alone.

One of the problems in assessing the severity of exposures to hand-transmitted vibration arises from the difficulty in quantifying the durations of exposures. For example, when applying the current standards it may not be agreed whether the predictions apply to a worker's estimate of the typical duration of daily exposure to vibration, or the average duration measured by an observer, which is sometimes much shorter. The differences between different estimates of exposure duration means that a dose-response relation based on duration alone (and shown in table 5 and fig 1) may not apply to other types of work. The accuracy with which exposure duration was estimated in this study (and others) is one of the principal areas of uncertainty (see below).

This study considered the cumulative duration of exposure and did not investigate how the distribution of durations of exposure to hand-transmitted vibration (on any day or over months and years) affects the development of finger blanching. It is possible that exposure severity may be affected by periods without vibration (during the day, or over months and years). Similarly, it is possible that current symptoms are more influenced by recent exposures than by exposures in the more distant past.

\section{Vibration magnitude}

From the models in table 5 it might be concluded that exposure duration could be a sufficient measure of exposure severity for users of the tools investigated in this study. The models in table 4 suggest that exposure duration in hours was a better predictor than exposure duration measured in years. The LR ratios obtained when fitting together the equivalent acceleration and duration of exposure in the models for table 4 (where acceleration and duration were fitted separately, see section on relation between VWF symptoms and exposure variables) have been compared with the LR ratios in table 5 (combinations of acceleration and exposure duration) to consider which type of model provided the better fit to the data. Using the Bayesan information criterion it seems that, in general, the models in table 4 provided better fits than those in table 5, at least from a statistical viewpoint ${ }^{24}$ (see table 7 ). However, it is recognised that maximising the fit of a model to available data does not always maximise the value of the model or, in this case, its relation to the underlying mechanisms of injury. Nevertheless, table 7 suggests that vibration magnitude plays a significant role in the prediction of VWF, even though to a lesser extent than duration of exposure.

\section{Differences between tools and occupations}

The analysis of alternative dose measures grouped all tools and jobs together. However, if a dose measure is to be used to reduce the risks from exposures to hand-transmitted vibration it must be applicable to an individual occupation and also to a specific tool. While the wide range of exposure severities among the 1557 workers helped to identify differences between the alternative dose measures, this might have arisen from high doses being caused mainly by, say, an occupation $A$ having long exposures to low magnitudes while occupation $B$ gave low doses from short exposures to higher magnitudes. 
Table 7 Differences in the Bayesan information criterion $(B \mid C)^{*}$ between logistic models assessing the association between VWF (binary outcome) and alternative measures of vibration exposure, while adjusting for age and smoking

\begin{tabular}{|c|c|c|c|c|}
\hline Dose & $\begin{array}{l}a_{h, w e q, 7)} \text { and total } \\
\text { hours }\end{array}$ & $\begin{array}{l}a_{h, u w(e q, T)} \text { and total } \\
\text { hours }\end{array}$ & $\begin{array}{l}a_{h, w e q, T} \text { and years } \\
\text { of exposure }\end{array}$ & $\begin{array}{l}a_{\text {huwleq, }, T)} \text { and years } \\
\text { of exposure }\end{array}$ \\
\hline$\Sigma \mathrm{t}_{\mathrm{i}}$ (hours) & 30.8 & 35.8 & -27.4 & 17.2 \\
\hline$\sum a_{\mathrm{w}} \mathrm{t}_{(}\left(\mathrm{ms}^{-2} \mathrm{~h}\right)$ & 18.6 & - & -39.5 & - \\
\hline$\sum a_{w i}{ }^{2} t_{i}\left(m^{2} s^{-4} h\right)$ & 59.5 & - & 1.31 & - \\
\hline$\sum a_{w i}{ }^{4} t_{i}\left(m^{4} s^{-8} h\right)$ & 78.3 & - & 20.1 & - \\
\hline$\sum \mathrm{a}_{\mathrm{uwwi}}^{\mathrm{i}} \mathrm{t}_{(}\left(\mathrm{ms}^{-2} \mathrm{~h}\right)$ & - & 14.7 & - & -38.3 \\
\hline$\sum a_{u w i}{ }^{2} t_{i}\left(m^{2} s^{-4} h\right)$ & - & 30.1 & - & -22.9 \\
\hline$\sum a_{u w i}{ }^{4} t_{i}\left(m^{4} s^{-8} h\right)$ & - & 54.9 & - & 1.99 \\
\hline
\end{tabular}

In the logistic regression models, vibration dose, equivalent acceleration, and duration of exposure (total hours or years) were included as quintile based design variables, assuming the lowest quintile as the

reference category.
* Strength of evidence favouring one model against another model on the basis of the value of the difference * Strength of evidence favouring one model against another model on the basis of the value of the differe
in $\mathrm{BIC}^{24}: 0-2=$ weak evidence; $2-6=$ positive evidence; $6-10=$ strong evidence; $>10=$ very strong evidence. Positive value $=$ model in the column is better than model in the row; negative value = model in the row is better than model in the column

While a dose measure may be found to be optimum for this mix of occupations, it might arise from occupation $A$ involving, say, a different hand grip than occupation $B$. The dose-response relation evolved could then present a misleading indication of the influence of the relations associated with magnitude, frequency, and duration.

Table 2 shows that most occupations contained overlapping ranges of exposure durations and acceleration magnitudes, suggesting that the 1557 subjects formed a fairly homogeneous group. When an occupational group variable was included in the multiple logistic regressions, intercepts were not significantly different for stone grinders, stone carvers, painters, boilermakers, and forestry workers. Both quarry drillers and caulkers (that is, those with the greatest VWF prevalence) showed different intercepts when compared with the above groups, while there was no difference in the intercepts when these two groups (quarry drillers and caulkers) were compared to each other.

Additional analysis (not presented) showed that the best overall dose-response model ( $\operatorname{dose}=\Sigma a_{\text {uwi }} t_{\mathrm{i}}$ ) gave a fit to the data as good (for the groups of dockyard painters, dockyard caulkers, and forestry workers) or better (for the stone carvers and dockyard boilermakers) than the other alternative dose measures. In these occupations (that is, dockyard painters, dockyard caulkers, forestry workers, stone carvers, and dockyard boilermakers) the dose measures with high powers of acceleration (i.e. $m>1$ ) were less satisfactory than measures in which $a$ and $t$ were given equal weight. This applied to both weighted and unweighted acceleration, with the exception of the dockyard painters. Stone grinders were the only occupation in which higher powers of frequency-weighted acceleration (i.e. $m>1$ ) were better. The stone grinders were the occupation with the lowest prevalence of VWF and the only group in which vibration exposure was limited to rotary tools. The measure of dose determined solely by the duration of exposure worked well in all groups, with the exception of the stone grinders.

\section{Uncertainties}

The doses were primarily calculated from root-mean-square acceleration values (for tool types) and lifetime exposure durations, in hours. Both quantities have several sources of uncertainty that will have contributed to uncertainty in the calculated doses.

The suitability of average magnitudes of hand-transmitted vibration depends on the accuracy of the measurements and whether they are representative of the exposures. ${ }^{25}$ In the present study, further uncertainties arise because the measurements were made on currently available tools used in a few operations: the tools used by workers, and the vibration mag- nitudes on the tools and their methods of use may have changed over the years. In the study of quarry/stone workers, however, data on current exposure to vibration was considered a reliable surrogate for past exposure as the type and design of most vibrating tools had remained fairly similar over time. ${ }^{14} 26$ In the study of forestry workers, vibration from nonantivibration chain saws previously used in the forest districts was measured to estimate cumulative vibration dose for men with long term saw vibration exposure.

In the studies, daily exposure duration and total years of tool use were estimated from information obtained by interviewing employees and employers and by consulting personnel employment records, when available. However, the assumed durations of exposure to hand-transmitted vibration were mainly dependent on the memories and impressions of the workers. There may be recall bias of lifetime exposures to hand-transmitted vibration, especially if there are any implications for either continued employment or compensation for injuries. In the present studies, the workers were aware that the results were confidential to the research teams and there were no issues of compensation or termination of employment arising from their responses. The investigation teams made themselves familiar with the jobs involved and were able to check the accuracy of some of the information provided. For example, in the case of chain sawyers, several information sources were used: workplace assessment questionnaires obtained by direct interviews with employers were compared with information provided by employees, employment records, and the amount of fuel used by the chain saws. The number of years during which the workers had been exposed to hand-transmitted vibration were constrained by their employment history and are likely to be more accurate than estimates of daily exposure duration. Some studies have found that worker estimates of the durations of daily exposures to hand-transmitted vibration tend to be greater than found by observation of tool users, and this bias seems to be greater for tools used intermittently. ${ }^{27}$ However, the likelihood ratio tests in table 4 show that the total operating duration (in hours) gave a stronger association with VWF than the exposure duration in years, suggesting that the study distinguished between individuals with low and high daily exposure durations. A systematic bias towards increased exposure duration should not affect the goodness of fit of a dose model. An overestimate of daily exposure duration will affect the absolute values of the doses at which effects are observed, but they may be the most appropriate estimates for those many situations where dose must be based on worker estimates of past exposure durations.

The reporting of health symptoms is also subject to uncertainty: blanching scores and dates of onset of symptoms may 
be affected by random or systematic errors. These errors should have little effect on the comparison of the merits of the different dose models unless there were systematic differences associated with the use of different tools. The cross sectional studies on which the current investigation is based may have been biased by some individuals leaving vibration exposed groups prior to the study as a result of the development of VWF (that is, the "healthy worker effect"). However, it is thought that in the populations studied this was small: alternative employers were often not available and the men continued to work with vibratory tools, although in some cases their exposures may have been reduced. For example, some dockyard workers who were not fit for normal work were given "light duties" and were included in the study. In the study of the quarry/stone workers, the registers of the companies showed that the level of employment was stable and there was little job mobility within the industry in the past 15 years. All the active dockyard workers, all the stone workers, and all the forestry workers participated in the investigations so that self selection was not a source of bias in the studies. Moreover, to reduce selection bias, former stone workers and forestry workers, who had belonged to the study groups, were traced and included in the study populations. Even if the studied populations were representative of users of the vibratory tools included in the study, they may not be representative of a wider population of potential tool users: susceptible subjects may not volunteer for such work or may leave work with vibratory tools for other reasons. However, this may not affect the suitability of the data for comparing alternative dose models for tools similar to those investigated.

The different dose models place differing importance on the accuracy of measuring exposure duration and acceleration magnitude. With higher powers of acceleration, it becomes more important to know the acceleration magnitude. Possibly, the difficulty in knowing the acceleration on the tools over a long period is one reason why the higher powers of acceleration produced less accurate dose models. The best dose model gave equal weight to acceleration magnitude and cumulative duration of exposure, implying that both should be known to a similar accuracy. Probably, for exposures on a single day, acceleration may often be known more accurately than the exposure duration. However, as vibration magnitudes have changed over the years it might be reasonable to suppose that somewhat similar percentage errors may apply to both measures. The finding of better dose-response models without the frequency weighting increases the importance of accurately measuring the higher frequencies of vibration: whereas frequencies above approximately $200 \mathrm{~Hz}$ rarely contribute to the weighted acceleration, frequencies as high as $500 \mathrm{~Hz}$ or greater may contribute to the unweighted acceleration. ${ }^{28}$

\section{Implications of findings}

Changing the frequency weighting from the current $W_{\mathrm{h}}$ characteristic has important implications for tool manufacturers, tool purchasers, tool users, and also scientists studying the development of diseases caused by hand-transmitted vibration. A simple change from frequency-weighted acceleration to unweighted acceleration will reverse the assumed rank order of severity of vibration on some tools.

The study suggests that a linear relation between r.m.s. acceleration and total exposure duration may be sufficient for evaluating the severity of vibration exposures. This would eliminate the need for the so called "energy equivalent" daily vibration magnitude that is difficult for employers and workers to understand and calculate. The linear relation would suggest more potential for control of the severity of daily vibration exposures by limiting exposure duration than with the present "second power" method (i.e. dose $=\Sigma a_{i}^{2} t_{i}$ ). Consequently, the reduction of vibration magnitudes (by engineering control and design of reduced vibration equipment) would have less effect on calculated exposure severity. Interestingly, the current study suggests that useful predictions of the development of finger blanching can be obtained without using a measure of vibration magnitude: total estimated exposure duration provided one of the best predictions. This suggests that current standards may be overly concerned with the importance of reducing vibration magnitude (by tool manufacturers) and underestimate the importance of reducing vibration exposure duration (by employers and employees).

It is clear that changing the frequency weighting and time dependency in current standards will have profound consequences. Any change would merit greater consideration of the consequences than was given when the original methods were proposed and standardised, and may not be justified without further evidence, including that from prospective studies.

The dose models investigated in this study were linear: the doses were proportional to a measure of duration and acceleration magnitude, with no threshold (or limiting value) for either magnitude or duration. In practice, exposures to low magnitudes of vibration are often ignored and short exposures are also sometimes neglected. It seems possible that the mechanisms associated with injury may be complex and not necessarily linear, such as found with acute vascular responses during and following exposure to hand-transmitted vibration..$^{29}$ It seems unlikely that a satisfactory dose measure can be developed solely from vibration magnitudes (that is, ignoring exposure duration), but it might be possible to develop a useful simple model based solely on cumulative duration of exposure to vibration above some threshold magnitude. The measures of dose appearing in the tables might be used to predict the severity of other exposures to handtransmitted vibration. For example, using exposure duration as a continuous variable, model 2 in table 4 predicts that after 3100 hours of exposure to hand-transmitted vibration approximately $17.5 \%$ (95\% CI 15.1 to $20.1 \%$ ) of persons will have developed VWF. This compares with an observed $17 \%$ prevalence, as shown in table 5 (dose $\Sigma t_{i}$ with a quintile midpoint of 3100 hours). However, since VWF is at least partially dependent on vibration magnitude, such simple predictions will not always apply.

\section{CONCLUSIONS}

When knowledge of exposures to hand-transmitted vibration is restricted to the total duration of exposure, and does not discriminate between exposures accumulated over the day and those accumulated over years, a dose formed from a linear relation between vibration magnitude, $a$, and exposure duration, $t$, can be appropriate for predicting the occurrence of VWF (i.e. dose $=\Sigma a_{i} t_{\mathrm{i}}$ ).

The accuracy of predictions of VWF was dependent on the frequency weighting, with poorer predictions when the currently recommended frequency weighting was employed. This suggests that more weight should be given in the standards to vibration at some intermediate or high frequencies relative to the weight given at low frequencies.

The findings suggest that improvements are possible to both the frequency weighting and the time dependency in current standards used to predict the development of VWF.

\section{Authors' affiliations}

M J Griffin, C M Nelson, Human Factors Research Unit, Institute of Sound and Vibration Research, University of Southampton, Southampton SO17 1BJ, UK

M Bovenzi, Department of Public Health Sciences, Clinical Unit of Occupational Medicine, University of Trieste, Centro Tumori, Via della Pieta' 19, 1-34129 Trieste, Italy

\section{REFERENCES}

1 International Organization for Standardization. Mechanical vibration-guidelines for the measurement and the assessment of human exposure to hand-transmitted vibration. ISO 1986:5349. Geneva: ISO, 1986. 
2 Miwa T. Evaluation methods for vibration effects. Part 4: Measurement of vibration greatness for whole-body and hand in vertical and horizontal vibration. Ind Health 1968;6:1-10

3 Brammer AJ. Dose-response relationships for hand-transmitted vibration. Scand J Work Environ Health 1986;12:284-8.

4 Anttonen $\mathbf{H}$, Virokannas $\mathrm{H}$. Hand vibration among snowmobile drivers and prediction of VWF by vibration standard. In: Dupuis $H, C$ hrist $E$, Sandover J, Taylor W, Okada A, eds. Proceedings of the 6th International Conference on Hand-Arm Vibration, Bonn, 1992. Published: HVBG, D-53754 Sankt Augustin, ISBN 3-88383-331-2, 875-883.

5 Dandanell R, Engström K. Vibration from riveting tools in the frequency range $6 \mathrm{~Hz}-10 \mathrm{MHz}$ and Raynaud's phenomenon. Scand J Work Environ Health 1986;12:338-42.

6 Bovenzi M, Franzinelli A, Strambi F. Prevalence of vibration-induced white finger and assessment of vibration exposure among travertine workers in Italy. Int Arch Occup Environ Health 1988;61:25-34.

7 Nilsson T, Burström L, Hagberg M. Risk assessment of vibration exposure and white fingers among platers. Int Arch Occup Environ Health 1989;61:473-81.

8 Starck J, Pekkarinen J, Pyykkö I. Physical characteristics of vibration in relation to vibration-induced white finger. Am Ind Hyg Assoc 1990:51:179-84

9 Griffin MJ. Handbook of human vibration. London: Academic Press, 1990.

10 Griffin MJ. Standards for the evaluation of hand-transmitted vibration and the prevention of adverse effects. In: Lundström $R$, Lindmark $A$, eds. Proceedings of the 8th International Conference on Hand-Arm Vibration, 9-12 June 1998, Umeå, Sweden, 2000. Arbetslivsrapport Nr 2000:4, ISSN: 1401-2928, 243-259.

11 Nelson CM Griffin M. Vibration-induced white finger in dockyard employees. Institute of Sound and Vibration Research, Technical Report 170, University of Southampton, 1989

12 Nelson CM, Griffin M. Comparison of predictive models for vibration-induced white finger. Proceedings of the 6th International Conference on Hand-Arm Vibration, In: Dupuis H, Christ E, Sandover J, Taylor W, Okada A, eds. Proceedings of the 6th International Conference on Hand-Arm Vibration, Bonn, 1992. Published: HVBG D-53754 Sankt Augustin, ISBN: 3-88383-331-2, 875-883

13 Bovenzi M, Franzinelli A, Mancini R, et al. Dose-response relation for vascular disorders induced by vibration in the fingers of forestry workers. Occup Environ Med 1995;52:722-30.

14 Bovenzi M. Italian Study Group on Physical Hazards in the Stone Industry. Hand-arm vibration syndrome and dose-response relation for vibration-induced white finger among quarry drillers and stonecarvers. Occup Environ Med 1994;51:603-11.

15 Griffin MJ. The effects of vibration on health. Institute of Sound and Vibration Research Memorandum 632, University of Southampton, 1982

16 International Organization for Standardization. Measurement and evaluation of human exposure to hand-transmitted vibration-Part 1: General guidelines. ISO 2001:5349-1. Geneva: ISO, 2001.

17 British Standards Institution. Measurement and evaluation of human exposure to vibration transmitted to the hand. BSI 1987:6842. London: BSI, 1987.

18 Fu VK. Estimating generalized ordered logit models. Stata Technical Bulletin 1998;44:27-30

19 Scott Long J, Freese J. Regression models for categorical dependent variables using Stata. College Station, TX: Stata Press, 2001.

20 Hosmer DW, Lemeshow S. Applied logistic regression, 2nd edn. New York: John Wiley \& Sons, 2000.

21 Mirbod SM, Yoshida H, Komura Y, et al. Prevalence of Raynaud's phenomenon in different groups of workers operating hand-held vibrating tools. Int Arch Occup Environ Health 1994;66:13-22.

22 Bovenzi M, Alessandrini B, Mancini R, et al. A prospective study of the cold response of digital vessels in forestry workers exposed to saw vibration. Int Arch Occup Environ Health 1998;71:493-8.

23 Anon. Criteria for a recommended standard. Occupational exposure to hand-arm vibration. Publication No. 89-106. Cincinnati: DHHS (NIOSH) 1989.

24 Raftery AE. Bayesan model selection in social research. In: Marsden PV ed. Sociological methodology. Oxford: Basil Blackwell, 1996:111-63.

25 Pitts PM. Measurement uncertainty in the evaluation of hand-arm vibration exposure in the workplace - an introduction to ISO 5349-2. Proceedings of the Institute of Acoustics 1999;21:9-15.

26 Taylor W, Wasserman D, Behrens V, et al. Effect of the air hammer on the hands of stonecutters. The limestone quarries of Bedford, Indiana revisited. Br J Ind Med 1984;41:289-95.

27 Palmer KT, Haward B, Griffin M, et al. Validity of self reported occupational exposure to hand-transmitted and whole body vibration. Occup Environ Med 2000;57:237-41

28 Griffin MJ. Measurement, evaluation, and assessment of occupationa exposures to hand-transmitted vibration. Occup Environ Med 1997:54:73-89.

29 Bovenzi M, Lindsell CJ, Griffin M. Response of finger circulation to energy equivalent combinations of magnitude and duration of vibration. Occup Environ Med 2001;58: 185-93.

\section{OEM web submission and review system}

I am pleased to inform authors and reviewers of the new online submission and review system at OEM. Developed by Highwire Press (CA, USA), Bench>Press is a fully integrated electronic system which uses the internet to allow rapid and efficient submission of manuscripts. It also allows the peer review process to be conducted entirely online. The main aim is to speed up the frequently frustrating progress from submission to publication.

Authors can submit their manuscript in any standard word processing software. Standard graphic formats accepted include: .jpg, .tiff, .gif, eps, etc. (Please note: multi page powerpoint files are not accepted by the BM Publishing Group.) The text and graphic files are automatically converted to PDF for ease of distribution and reviewing purposes. Authors are asked to approve their submission before it formally enters the reviewing process. On approval, the submission is passed to the editor and/or reviewers via the web. All transactions are secure.

To access the system click on "SUBMIT YOUR MANUSCRIPT HERE" on the OEM homepage: http://www.occenvmed.com, or you can access the submission site directly at http://submitoem.bmijournals.com.

We are very excited with this new development and would encourage authors and reviewers to use the system where possible. It really is simple to use and should greatly improve on the current peer review process. Full instructions can be found on Bench>Press http://submitoem.bmijournals.com and OEM online at http://www.occenvmed.com. Please contact Natalie Davies, Project Manager, ndavies@bmigroup.com.

Anne Cockcroft 